\title{
PENAMBAHAN PEKTIN, GULA, DAN ASAM SITRAT DALAM PEMBUATAN SELAI DAN MARMALADE BUAH-BUAHAN
}

\author{
Fesdila Putri Nurani \\ UPN "Veteran" Jawa Timur \\ fesdila.tp@upnjatim.ac.id
}

\begin{abstract}
Quality degradation due to the process of respiration as well as physical, chemical and biological damage to the fruit is very undesirable because it caused indirectly shorten the shelf life of the fruit. Damaged fruit will have a low selling value. Various attempts were made to overcome these problems including of fruit chips, sweets, to fruit leather. In addition to these methods, fruit can also be processed into bread spread ingredients such as jam and marmalade. Jam is a thick or semi-solid food product made from crushed or chopped of fruit with added some sugar. Marmalade is a semi-solid food product made from fruit juice, sugar, citric acid, and includes pieces of fruit or fruit skin. Marmalade is generally made from citrus fruits, but nowadays marmalades are also made from other fruits. Both of jam and marmalade products involve the heating process and the use of high concentrations of sugar as a preservative. Several factors that influence the making of jam and marmalade include pectin, sugar, water and the presence of acids which are very influential in gel formation.
\end{abstract}

Keywords : fruit; jam; marmalade; preservation; sugar

\begin{abstract}
Abstrak
Penurunan mutu akibat proses respirasi maupun adanya kerusakan fisik, kimiawi maupun biologis pada buah sangat tidak diinginkan karena secara tidak langsung dapat memperpendek masa simpan buah. Buah yang rusak akan memiliki nilai jual yang rendah. Berbagai upaya dilakukan untuk mengatasi permasalahan tersebut diantaranya pengolahan keripik buah, manisan, hingga fruit leather. Selain cara tersebut, buah juga dapat diolah menjadi bahan olesan roti seperti selai dan marmalade. Selai adalah produk makanan yang berbentuk gel, bersifat kental atau semi padat dibuat dari hancuran buah dan gula. Sedangkan marmalade adalah produk makanan bersifat semi padat yang terbuat dari sari buah, gula, asam sitrat, dan menyertakan potongan buah atau kulit buah. Marmalade umumnya dibuat dari buah jeruk, namun seiring perkembangan jaman, marmalade juga dibuat dari buah yang lain. Baik produk selai dan marmalade melibatkan proses pemanasan serta penggunaan gula dengan konsentrasi yang tingi sebagai bahan pengawetnya. Beberapa faktor yang mempengaruhi pembuatan selai dan marmalade antara lain kandungan pectin, gula, air serta adanya asam yang sangat berpengaruh terhadap pembentukan gel.
\end{abstract}

Kata kunci: buah; gula; marmalade; pengawetan; selai. 


\section{Latar Belakang}

Indonesia merupakan negara tropis dimana memiliki keanekaragaman hayati yang tinggi, diantaranya buah-buahan. Banyak sekali dijumpai berbagai jenis buah dengan bermacam-macam varietas yang dapat tumbuh di Indonesia. Buahbuahan juga sudah menjadi salah satu hal yang lazim dikonsumsi oleh masyarakat sehari-hari. Buah-buahan dikenal memiliki nilai gizi yang baik, diantaranya karbohidrat, prtotein, serat serta diketahui memiliki kadar air yang cukup tinggi. Kadar air yang tinggi seringkali menjadi masalah dalam proses penyimpanan buah segar. Suhu udara yang tinggi serta kelembaban yang relative tinggi di Indonesia menjadikan buah seringkali tidak memiliki umur simpan yang panjang akibat mudah sekali menjadi busuk.

Berbagai upaya untuk memperpanjang masa simpan buah telah banyak dilakukan. Umumnya, yang sering sering dijumpai adalah dengan pembuatan keripik buah. Dalam penelitiannya, Lastriyanto dkk (2016) menyebutkan bahwa resiko kerusakan apel manalagi rentan terjadi pada saat panen raya. Untuk menanggulangi kerusakan tersebut, apel manalagi kemudian diolah menjadi keripik melalui penggorengan vakum. Suryanto (2018) juga menyebutkan permasalahan yang sama, dimana buah nangka yang telah dipanen akan mengalami penurunan mutu karena respirasi, sehingga untuk menanggulangi hal itu, nangka diolah menjadi keripik. Selain dalam bentuk keripik, upaya pengawetan buah juga dilakukan dengan cara lain seperti pembuatan manisan buah papaya kering (Wati dkk, 2016), pembuatan manisan nanas (Nofriati, 2013), pembuatan fruit leather dari campuran buah sirsak dan melon (Risti \& Herawati, 2017).

Selain produk makanan ringan, pengawetan buah juga dapat dilakukan dengan pengolahan selai ataupun marmalade. Pada dasarnya selai terbuat dari campuran dari 45 bagian buah berupa cacahan atau potongan buah sedangkan 55 bagian lainnya merupakan gula yang kemudian akan mengental dan membentuk stuktur semi padat (Gaffar dkk, 2017). Novita dkk (2017) menyebutkan bahwa marmalade merupakan makanan semi padat dan juga membentuk gel akibat dari adanya interaksi antara sari buah sebagai bahan utama, gula atau sukrosa, asam sitrat, pektin serta potongan buah. Baik selai maupun marmalade merupakan produk olesan roti berbasis buah. Pembuatan selai dan marmalade melibatkan proses pemanasan serta pengawetan dengan gula. Hal ini dilakukan untuk mengurangi resiko kerusakan produk akibat kontaminasi mikrobiologis.

Pembuatan selai dan juga marmalade umumnya menggunakan bahan buah yang memiliki kandungan pectin. Pektin merupakan senyawa polisakarida larut air yang mampu membentuk gel pada produk selai dan marmalade. Pada beberapa jenis buah dengan kandungan pectin rendah umumnya akan ditambahkan pectin komersil agar terbentuk gel yang konsisten. Bahan lain yang digunakan dalam pembuatan selai dan marmalade adalah gula. Gula berperan dalam pembentukan gel. Selain itu, gula juga berfungsu sebagai pengawey alami yang mencegah pertumbuhan kapang pada produk selai dan marmalade. Selain pectin dan gula, bahan lain yang berperan dalam pembuatan selai dan marmalade adalah adanya pengasam. Pengasam ditambahkan untuk memperoleh $\mathrm{pH}$ di kisaran 2.8-3.4 untuk membentuk gel yang konsisten, memperkuat rasa buah serta meningkatkan nilai total asam. Umumnya, pengasam 
yang sering digunakan dalam pembuatan selai dan marmalade adalah asam sitrat. Selain asam sitrat, pengasam lainnya yang dapat ditambahkan dalam produk selai maupun marmalade antara lain asam malat, asam tartaratm asam laktat, asam fumarat ataupun asam fosfat. Desrosier (1988) menjelaskan ada 4 substansi penting dalam pembentukan gel pada pembuatan marmalade, yaitu sari buah jeruk, pektin, gula, asam dan air.

\section{Metode}

Dalam penelitiannya, Amelia dkk (2016) menjelaskan mengenai pembuatan selai buah jambu biji merah yang telah dilakukannyan antara lain pengupasan biji buah jambu biji merah, penimbangan sebanyak $500 \mathrm{~g}$, pencucian, pengecilan ukuran dan penghancuran dengan menggunakan blender. Kemudian dilakukan penambahan air serta penyaringan dan penambahan asam sitrat dan pektin. Setelah itu dilakukan proses pemasakan pada suhu $60-65^{\circ} \mathrm{C}$ selama 3-5 menit untuk melarutkan asam sitrat dan pectin. Tahap selanjutnya penambahan sukrosa serta pemanasan pada suhu 100$110^{\circ} \mathrm{C}$ selama $20-25$ menit sambil dilakukan pengadukan hingga mengental. Sesekali dilakukan pengujian kekentalan dengan spoon test untuk menentukan kekentalan. Setelah kekentalan yang diinginkan tercapai, selai segera diangkat dan dikemas dalam botol.

Fasogbon et al.(2013) dalam penelitiannya menggunakan buah nanas yang telah didehidrasi secara osmosis. Langkah pertama yang dilakukan adalah melakukan rehidrasi pada potongan nanas kering kemudian dihancurkan dengan blender dengan penambahan air dengan perbandingan $18 \mathrm{~g}$ air dan $34 \mathrm{~g}$ nanas. Kemudian ditambahkan $65 \%$ gula, $0.4 \%$ pectin, dan $0.4 \%$ asam sitrat. Campuran tersebut kemudian diipanaskan pada suhu $80-100^{\circ} \mathrm{C}$ selama $22-23$ menit. Selai yang sudah jadi, dimasukkan dalam botol yang telah di sterilisasi dan disimpan rapat.

Penelitian mengenai marmalade jeruk kalamansi yang dilakukan oleh Novita dkk (2017) memiliki metode sebagai berikut : bahan baku berupa sari sari jeruk murni seberat $200 \mathrm{~g}$, ditambahkan dengan $100 \mathrm{~g}$ air. Kemudian ditambahkan sukrosa dan pectin. Semua bahan dihomogenkan, baru kemudian dilakukan pemanasan pada suhu $70^{\circ} \mathrm{C}$ selama kurang lebih 20 menit hingga mengental dan membentuk gel. Analisis yang dilakukan meliputi kekentalan,daya oles, kadar air, $\mathrm{pH}$, serta total padatan terlarut

Adityas dkk (2018) menjelaskan bahwa untuk mendapatkan marmalade kulit jeruk sunkist dapat dilakukan dengan merebus kulit kulit jeruk Sunkist dengan air selama \pm 20 menit dengan suhu $80^{\circ} \mathrm{C}$ hingga teksturnya lunak dan pektinnya keluar. Kemudian dicampur dengan potongan buah jeruk sunkist, nanas, gula sesuai perlakuan dan air perasan jeruk nipis. Lalu dipanaskan pada suhu $105^{\circ} \mathrm{C}$ selama \pm 40 menit sehingga marmalade mengental. Kemudian marmalade yang telah mengental dimasukkan ke dalam botol steril.

\section{Pektin}

Pektin adalah senyawa polimer yang dapat mengikat air, membentuk gel atau mengentalkan cairan bersama gula dan asam (Puspitasari, dkk. 2008). Menurut BPOM (2013) pada proses pembuatan produk pangan, pectin dapat digunakan sesuai kebutuhan produk, tidak terdapat proporsi yang tetap dalam penggunaanya.

Amelia dkk (2016) dalam penelitiannya menyebutkan jumlah pectin akan mempengaruhi daya oles selai jambu biji merah. Konsentrasi pectin yang digunakan dalam penelitian tersebuta antara lain $0 ; 0,2 ; 0,4 ; 0,6 ; 0,8 ; 1 \%$. Hasil 
yang diperoleh menunjukkan makin tinggi pectin yang ditambahkan makin tinggi daya olesnya. Namun konsentasi pectin yang terlalu tinggi akan menyebabkan gel semakin keras sehingga akan sulit untuk dioles. Perlakuan terbaik didapatkan dengan penambahan pectin sebesar $1 \%$ yang mengahsilkan daya oles sebesar 2,72.

Penelitian yang dilakukan oleh Novita dkk (2017) mengamati karakteristik marmalade jeruk kalamansi dengan kajian konsentrasi pectin dan sukrosa. Dalam penelitian tersebut, dijelaskan bahwa perlakuan penambahan pectin berpengaruh pada kekentalan marmalade. Perlakuan terbaik didapatkan dengan penambahan pectin sebesar 2,25\%. Pektin berfungsi dalam pembentukan gel, khususnya pada buah-buahan yang memiliki kandungan pectin yang rendah, sedangkan air pada bahan diikat oeh gula sehingga gel terbentuk dan memberikan kesan kental yang baik. (Sundari dan Komari, 2010).

\section{Sukrosa}

Salah satu bahan yang banyak dilibatkan dalam pengawetan dan pembuatan produknmpangan adalah gula. Beberapa bentuk gulan yang umum dijumpai adalah sukrosa, fruktosa, glukosa, laktosa, maupun dekstrosa. Fungsi gula pada pembuatan selai utamanya adalah untuk membentuk tekstur gel yang baik, kenampakan produk yang menarik serta memberikan rasa dan flavor. Gula berperan penting dalam membentuk gel karena berinteraksi dengan pectin yang berasal dari buah-buahan (Yuliani, 2011).

Menurut Siregar (2009) penambahan gula akan mempengaruhi keseimbangan pectin dan air, pektin akan menggumpal dan membentuk suatu serabut halus, kontinuitas dan kepadatan ditentukan oleh banyaknya kadar pektin dan gula yang digunakan.
Novita dkk (2017) dalam penelitiannya menyebutkan penambahan sukrosa sebanyak 95\% signifikan berpengaruh terhadap nilai total padatan terlarut (TPT) marmalade jeruk kalamansi. Kehadiran pectin dan sukrosa diduga menjadi komponen yang menyusun total padatan terlarut.

Penambahan sukrosa pada pembuatan selai jambu biji merah yang dilakukan oleh Amelia dkk (2016) menunjukkan pengaruh yang nyata terhadap nilai kadar air selai yang dihasilkan. dalam penelitian ini, konsentrasi sukrosa yang digunakan adalah 40\%, 50\% dan 60\%. Perlakuan terbaik didapatkan dari penambahan sukrosa sebesar $60 \%$. Hal ini disebabkan karena sukrosa bersifat higroskopis (mengkikat air) sehingga penambahan sukrosa yang semakin meningkat konsentrasinya menyebabkan terikatnya sebagian besar air bebas.

\section{Asam Sitrat}

Beberapa faktor diketahui mempengaruhi proses pembentukan gel dengan kekenyalan dan kekuatan tertentu, antara lain: konsentrasi pectin, $\mathrm{pH}$, ipn kalsium, suhu pemanasan, serta jumlah sukrosa. Faktor yang mempengaruhi lebarnya kisaran kekentalan larutan pectin adalah jumlah pectin, garam serta ukuran rantai asam poligalakturonat (Yulistiani dkk., 2011). Pada pembuatan selai dan marmalade, umumnya ditambahkan pengasan salah satunya asam sitrat agar terbentuk gel yang yg konsisten.

Winarno et al (1984) menyebutkan salah satu asidulan yang dapat berperan sebagai penegas rasa dan mampu menyamarkan "after taste" yang kurang disukai adalah asam sitrat. Asam sitrat juga dapat mengatur $\mathrm{pH}$ dalam hal ini menurunkanj $\mathrm{pH}$ sehingga dapat mencegah 
aktifnya fenolase dan juga dapat berperan sebagai pengkelat unsur $\mathrm{Cu}$ dalam enzim (Apandi, 1984)

Pada pembuatan selai tempurung kelapa yang dilakukan oleh Yuliani (2011), asam sirat menunjukkan interaksi dengan pectin dan menujukkan pengaruh pada total gula, kadar pektin, total asam, kadar air, kekentalan, dan derajat keasaman. Perlakuan terbaik pada penelitian tersebut adalah selai tempurung kelapa muda dengan penambahan pektin $0,75 \%$ dan asam sitrat $0,50 \%$. Adanya interaksi antara gula dan asam sitrat juga terjadi pada penelitian mengenai selain kulit buah naga merah yang dilakukan oleh Prasetya (2018). Dalan penelitiannya, Prasetya (2018) menyebutkan bahwa perlakuan penambahan gula sebesar $50 \%$ dan asam sitrat sebesar $0,9 \%$ memberikan respon terbaik dari segi rasa dan penerimaan oleh panelis.

\section{Kesimpulan}

Pembentukan gel pada selai maupun marmalade dipengaruhi oleh beberapa faktor, antara lain kandungan pectin dalam bahan, konsentrasi sukrosa yang ditambahkan, serta adanya asam. Pektin dapat ditambahkan pada buah atau bahan yang kandungan pektinnya rendah. Penambahan pectin, sukrosa dan asam dalam konsentrasi tertentu akan mempengaruhi karakteristik fisik seperti viskositas dan daya oles, karakter kimiawi seperti kadar air dan nilai total padatan terlarut (TPT) serta mempengaruhi penerimaan konsumen terhadap produk.

\section{Daftar Pustaka}

Adityas, E.W.P., Kurniawati, L., Mustofa, A. 2018. Karakteristik Marmalade Jeruk Sunkist (Caridina propinqua)-
Nanas (Ananas comosus) Dengan Variasi Penambahan Gula. Jurnal JITIPARI Vol 4: 104-111

Amelia, O., Astuti, S., \& Zulferiyenni. 2016. Pengaruh Penambahan Pektin dan Sukrosa Terhadap Sifat Kimia dan Sensori Selai Jambu Biji Merah ( Psidium guajava L.). Prosiding Seminar Nasional Pengembangan Teknologi Pertanian Politrknik Negeri Lampung ISBN: 978-60270530-4-5 hal 149-159

Apandi,M.1984. Teknologi Buah dan Sayur. Alumni. Bandung

Badan Pengawas Obat dan Makanan Republik Indonesia. 2013. Peraturan BPOM No.202013. Batas Maksimum Penggunaan Bahan Tambahan Pangan Pengemulsi.Jakarta

Beatrice M. Fasogbon, Saka O. Gbadamosi and Kehinde A. Taiwo. 2013. Studies on the Chemical and Sensory

Desrosier, N. W. 1988. Teknologi Pengawetan Pangan. Penerjemah M. Muljohardjo. UIPress. Jakarta

Gaffar, R., Lahming, Rais, M. 2017. Pengaruh Konsntrasi Gula Terhadap Mutu Selai Kulit Jeruk Bali (Citrus maxima). Jurnal Pendidikan Teknologi Pertanian, Vol. 3: S117S125

Lastriyanto, A., Sumardi ., R.Y., Melati, R.M. 2016. Karakterisasi Kimia Keripik Apel Manalagi Hasil Penggorengan Vakum Dengan Menggunakan Minyak Goreng Berulang. Jurnal Keteknikan Pertanian Tropis dan Biosistem Vol. 4 No. 2: 157-172

Nofriati, D. 2013. Kajian Pengawetan Manisan Kering Buah Nanas Ananas comosus L. Merr) Selama Masa Penyimpanan. Jurnal Agroindustri ISSN 2088 - 5369 Vol. 3 No. 2: 77 $-82$ 
Novita, T., Tutuarima, T. \& Hasanuddin.2017. Sifat Fisik dan Kimia Marmalade Jeruk Kalamansi (Citrus microcarpa) : Kajian Konsentrasi Pektin dan Sukrosa. Jurnal Eksakta Vol. 18 No. 2 e ISSN 2549-7464.

Pandiangan, A., Hamzah, F. \& Rahmayuni. 2017. Pembuatan Selai Campuran Buah Pepaya dan Buah Terung Belanda. Jom Fakultas pertanian Vol. 4 No. 2

Prasetya, D. N. 2018. Kajian Perbandingan Konsentrasi Gula dan Asam Sitrat Terhadap Sifat Kimia dan Organoleptik Selai Kulit Buah Naga Merah (Hylocereus polyrhizus). Skripsi. Universitas Bandar Lampung

Properties of Jam from Osmotically Dehydrated Pineapple Slices. British Journal of Applied Science \& Technology 3(4): 1327-1335

Puspitasari, D., N., Datti, dan L.,Edahwati. 2008. Pengolahan Sumber Daya Alam DanEnergi Terbarukan (Ektraksi Pektin dari Ampas Nanas). Surabaya, MakalahSeminar Nasional Soebardjo Brotohardjono, 18 Juni 2008

Risti, A.P. \& Herawati, N. 2017. Pembuatan Fruit Leather Dari Campuran Buah Sirsak (Annoma muricata L.) dan Buah Melon (Cucumis melo L.). Jom Fakultas Pertanian, Vol 4 No2: 1-15

Siregar, R., 2009. Pengaruh Konsentrasi Natrium Benzoat dan Lama PenyimpananTerhadap Mutu Marmalade Sirsak (Anona muricata $L)$.

FakultasPertanian.Universitas

Sumatra Utara, Medan

Sundari, D., dan Komari. 2010. Formulasi Selai Pisang Raja Bulu Dengan Tempe Dann DayaSimpannya. Puslitbang Gizi dan Makanan, Badan Litbangkes, Kemankes RI. Vol.33 (1) No. 1 : 93-101.
Suryanto, R. 2018. Rendemen dan FisikoKimia Keripik Nangka (Arthocarpus sp) Berdasar Masa Masak Optimal Buah. Indonesian Green Technology Journal E-ISSN. 2338-1787 ISSN. 2355-4010: 1-5

Wati, H., Jaya, J. D., Lestari, E. 2016. Optimasi Manisan Buah Pepaya Kering. Jurnal Teknologi AgroIndustri ISSN 2407-4624 Vol 3 No. 1: $8-21$

Winarno, 1992. Kimia Pangan dan Gizi. PT. Gramedia Pustaka Utama. Jakarta

Yuliani, H.R. 2011. Karakterisasi Selai Tempurung Kelapa Muda. Prosiding Seminar Nasional Teknik Kimia "Kejuangan" Pengembangan Teknologi Kimia untuk Pengolahan Sumber Daya Alam Indonesia ISSN 1693 - 4393, hal DO 1-6.

Yulistiani, R., Murtiningsih dan Munifa. 2011. Peran Pektin dan Sukrosa Pada Selai Ubi Jalar Ungu. Jurnal Teknologi Pangan 5:114-120. 